\section{El problema del sentido en el diálogo entre ciencia y religión*}

\author{
Carlos Miguel Gómez \\ Universidad del Rosario, Colombia \\ http://orcid.org/0000-0001-6806-7058
}

RECIBIDO: 13-07-17. APROBADO: 23-03-18
The Problem of Meaning in the Dialogue between Science and Religion

AвsTRACT: This paper critically explores the thesis according to which the main difference between science and religion is that while the former seeks to explain the causal order of the world, the latter deals with giving meaning to the totality of what exists and to individual experiences and actions. In the first part, it shows that explaining and giving meaning are solidarity endeavours, which cannot be easily separated either in science or in religion. Likewise, it finds the central issue of the dialogue between both domains in the question of the origin of meaning. In the second part, it argues against the social constructionist assumption according to which all meanings are entirely a human product. Finally, some aspects are pointed out about which the sciences and Christianity can talk about the existence of transcendent meaning in both nature and human life.

Keywords: Explanation and understanding; social constructionism; antirealism; imago Dei; Christianity and social sciences.

\section{Cómo CITAR:}

Gómez, Carlos Miguel. "El problema del sentido en el diálogo entre ciencia y religión”. Theologica Xaveriana 187 (2019): 1-23. https://doi.org/10.11144/ javeriana.tx69-187.psdcr

\title{
RECONOCIMIENTO
}

El artículo hace parte del proyecto "Social Construction and the Created Character of Human Beings" del Grupo CETRE (integrado por las universidades Javeriana, Rosario y Nacional de Colombia), el cual fue financiado con una beca del proyecto Science, Philosophy and Theology in Latin America del Ian Ramsey Centre, de Oxford University (2015-2017).

\section{*Artículo de investigación}

${ }^{a}$ Autor de correspondencia. Correo electrónico: carlos.gomezr@urosario.edu.co 


\section{Explicar y dar sentido}

Una tesis común en la discusión actual sobre las relaciones entre ciencia y religión consiste en afirmar que la diferencia fundamental entre estos dos dominios reside en que mientras que la primera busca explicar los fenómenos del mundo material mediante la descripción del orden causal en el que se insertan, la segunda ofrece un marco total de sentido en el que se pueden incluir tanto las experiencias como los saberes particulares. De esta manera se busca otorgar a cada dominio su función particular, de un modo que consiga captar y respetar la particularidad de lenguajes, propósitos y métodos de cada cual y evite simplemente contraponerlas como dos intentos necesariamente antagónicos por explicar el mundo.

A esto se suma el que la religión, además de relacionarse con el sentido del mundo como totalidad, se ocupa de la salvación, de modo que ver en las afirmaciones religiosas un intento por explicar la realidad puede resultar en serias malinterpretaciones. En este sentido es célebre la anotación de Galileo en una carta a la duquesa Cristina: "La Biblia enseña cómo llegar al cielo; no cómo funcionan los cielos”. En consecuencia, sería de poca importancia que lo que solo en apariencia es una explicación resulte falso o problemático de cara a mejores explicaciones, como la científica, pues la intención de la creencia religiosa no sería, en primer lugar, ofrecer explicaciones ${ }^{1}$.

En efecto, vale la pena tener siempre presente que -como ha sido mostrado en trabajos recientes- la idea según la cual el lenguaje religioso puede ser explicativo y, en general la religión consiste en una serie de doctrinas y teorías sobre el mundo que pueden ser verdaderas o falsas es relativamente reciente y tiene validez sobre todo en Occidente.

Solo a partir del siglo XVIII -y con especial fuerza en el XIX- esta idea de la religión como explicación se instaura con fuerza en la cultura occidental, reemplazando el sentido propio del término religio que en la Antigüedad y la Edad Media designaba la disposición interior de piedad y se utilizaba como adjetivo para describir el culto dirigido hacia la divinidad adecuada o el estilo de vida propio de las órdenes religiosas ${ }^{2}$. Como señala Cantwell Smith, el uso original de la expresión vera religio se refiere al

\footnotetext{
${ }^{1}$ Sobre esto hay una larga discusión entre dos posturas: la de quienes afirman que la creencia religiosa no cumple una función explicativa, para negar del todo que tenga valor cognitivo, y más bien le asignan funciones enteramente éticas o vinculadas a una forma de vida (ver a Phillips, Religion Withouth Explanation); y la de quienes no van tan lejos, y sin negar que la creencia religiosa tenga valor epistémico afirman que puede no ser explicativa porque la creencia en Dios en particular es una creencia básica cuya función no es dar cuenta de cómo es el mundo (ver a Plantinga, Warranted Christian Belief).

${ }^{2}$ Harrison, The Territories of Science and Religion, 7; Smith, The Meaning and End of Religion, 24ss.
} 
modo apropiado de llevar a cabo el culto divino y no a un sistema de creencias que dan cuenta adecuada del modo de ser del mundo ${ }^{3}$.

Sin embargo, la separación tajante entre ciencia y religión a partir de la función explicativa de la una y la tarea dadora de sentido y soteriológica de la otra es problemática, pues entre explicar y dar sentido es imposible establecer una diferenciación excluyente ${ }^{4}$. Hay por lo menos tres razones para esto:

- En primer lugar, como han mostrado con especial fuerza las ciencias sociales actuales, la comprensión es un momento y una condición de la explicación 5 . Esto es así porque las causas de las acciones humanas -al menos parcialmente- son razones que los agentes comprenden y hacen parte de un entramado de significaciones que el investigador social debe reconstruir. En este sentido, la diferencia entre explicar y comprender -central en el origen de las ciencias humanas, tal y como las comprendía Dilthey- no puede ya aplicarse sin más para distinguirlas de las ciencias naturales. Las ciencias sociales son también explicativas, sin renunciar por ello a su fundamental orientación hacia la comprensión.

- $\quad$ En segundo lugar, las ciencias naturales no pueden pensarse como meramente explicativas, y excluir de ellas toda dimensión de sentido. Autores como Husserl y Heidegger nos han enseñado que la investigación científica de la naturaleza presupone un horizonte de precomprensión, es decir, una manera de entender lo real y determinar lo que va a ser estudiado, el cual no se deriva ni se explica mediante la ciencia, sino que debe ser siempre tomado por dado por ella como la base a partir de la cual se puede llevar a cabo cualquier investigación.

No puede haber explicación científica en el vacío, es decir, en ausencia de alguna interpretación de lo que va a ser estudiado, de aquello que cuenta como natural y sirve para establecer tanto el objeto de estudio como los criterios mismos de la investigación; esto es, en palabras de Husserl, el mundo de la vida que establece la base de verdad y validez a la que los científicos se refieren constantemente en su actividad y en cuanto seres humanos ${ }^{6}$.

- Finalmente, la dicotomía entre explicar y dar sentido se derrumba porque la explicación científica puede comprenderse ella misma como un intento por dar sentido que sería solidaria con los intentos religiosos, los cuales pueden también comprenderse como intentos de explicación en otro nivel.

${ }^{3}$ Ibíd., 29.

${ }^{4}$ Gómez, "Fe y conocimiento. Investigación sobre la función epistémica de la creencia religiosa", 19-44.

${ }^{5}$ Bhaskar, The Possibility of Naturalism, 18-24; 154-168.

${ }^{6}$ Husserl, The Crisis of European Sciences and Transcendental Phenomenology $\$ 33,34$. 
Esto cuestiona un elemento de un relato ampliamente extendido en la Modernidad sobre la relación entre la ciencia y el sentido, según el cual el avance y predominio de la visión científica del mundo sería responsable de la pérdida de la visión cristiana de la realidad, una visión en la que la naturaleza, el cosmos y la vida humana están organizadas en un todo significativo. En efecto, al ocuparse principalmente del estudio de leyes causales del universo material, la ciencia no se opone ni excluye por principio una visión del mundo con sentido, si bien no puede por ella misma ocuparse de cuestiones típicamente vinculadas con el sentido, como el valor y el propósito de lo real'.

Alister McGrath defiende esta posición. Para él es claro que la religión -y en particular el cristianismo- tiene una dimensión explicativa fundamental. Porque si bien el mensaje de los evangelios se orienta hacia producir una transformación en los seres humanos mediada por la fe, "es claro que [esta salvación y redención] se extiende también a la mente humana y su encuentro con la realidad". ${ }^{8}$ En este sentido, la fe cristiana tiene la capacidad de generar un cambio en la manera como comprendemos el mundo que no es indiferente al propósito de la salvación, ni puede simplemente ser independiente de nuestros otros modos de conocer la realidad.

Ahora bien, la dimensión explicativa del cristianismo ocurre en un nivel diferente, más englobante y total, que el de las explicaciones científicas: se trata del nivel de lo que denomina los grandes relatos e imágenes integradoras de lo real (the big picture $^{9}$. En este sentido, el conflicto entre ciencia y religión es superado, no porque la religión deba comprenderse de un modo que excluya su función explicativa, sino más bien porque sus explicaciones ocurren en un nivel diferente del de la ciencia: el de las "preguntas últimas", que tienen que ver con asuntos como el propósito de la vida y la realidad (¿para qué estamos aquí? ¿ Hacia dónde se dirige todo esto?), la identidad (¿quién soy?), el valor (¿qué tiene importancia?), la vida buena y cuestiones semejantes que transcienden los límites de la investigación científica ${ }^{10}$.

Lo clave en la postura de McGrath consiste en que si bien las explicaciones religiosas superan los límites que son infranqueables para la investigación científica, esto no significa que por ello se opongan a la razón, ni que las teorías científicas no puedan también leerse como resonando con (aunque nunca demostrando) la visión

\footnotetext{
${ }^{7}$ Polanyi, Meaning, 161ss.

${ }^{8}$ McGrath, Science and Religion. A New Introduction, 57. Mi traducción.

${ }^{9}$ Ídem, Surprised by Meaning. Science, Faith and How We Make Sense of Things, 1.

${ }^{10}$ Ibíd., 38ss; 104ss.
} 
cristiana del mundo ${ }^{11}$. Ante todo, las explicaciones religiosas y las científicas tienen en común su estructura epistémica que puede ser comprendida como la de una abducción o inferencia a la mejor explicación. La estructura de esta inferencia, inicialmente investigada por Charles Sanders Peirce, puede formularse de la siguiente manera:

1. Un hecho o fenómeno $\mathrm{X}$ ocurre y es enigmático.

2. Si A fuera el caso, entonces $\mathrm{X}$ no sería enigmático (podría ser comprendido, explicado).

3. Por tanto, es probable que A sea el caso ${ }^{12}$.

Según McGrath, tanto las explicaciones científicas como las religiosas compartirían esta lógica abductiva. Ambas nos ofrecerían un marco o modelo que arroja luz sobre un aspecto enigmático de la realidad (en el caso de la religión, sobre el enigma mismo de lo real, el sorpresivo hecho de que exista algo en lugar que nada). Consecuentemente, la verdad de una explicación en cualquiera de los dos ámbitos tiene que ver, más que con una prueba o verificación definitiva, con su capacidad para dar sentido (es decir, en este caso, de explicar, de hacer comprensible) el ámbito de lo real del que trata, uniendo elementos dispares y en apariencia desconectados.

Las explicaciones religiosas serían así marcos de sentido que buscan ofrecer una perspectiva total ${ }^{13}$, es decir, una visión integradora de lo real que no solo hace posible una forma de vida basadas en ellas, sino que además permitiría dar cuenta de los presupuestos mismos de la investigación científica: que el universo tenga un orden y sea inteligible.

Desde mi punto de vista, la postura de McGrath deja sin resolver un par de cuestiones de las cuales depende en buena medida la relación entre las ciencias y las religiones respecto del asunto del sentido. Por un lado, las metáforas de McGrath sobre las explicaciones religiosas como "marcos de sentido" o "lentes" que nos permiten descubrir en la realidad un estructura y propósito profundos, implican el reconocimiento de que hay diferentes perspectivas posibles. Este es un tema común en la filosofía contemporánea que reflexiona sobre tal pluralidad de marcos de sentido o esquemas conceptuales e indaga sobre el significado de la relatividad conceptual aquí implicada. Lo que sea el mundo y lo que cuenta como real y significativo depende del marco de sentido que utilicemos para comprenderlo. No hay, al menos para el ser humano, una realidad no interpretada.

\footnotetext{
${ }^{11}$ Ibíd., 71.

${ }^{12}$ Ibíd., 10.

${ }^{13}$ Clayton, Explanation from Physics to Theology, 121 ss.
} 
Como señala McGrath, esto no implica necesariamente caer en el relativismo, pues es posible establecer criterios para evaluar marcos de sentido rivales, por ejemplo, la capacidad de la teoría de vincular eventos y elementos dispares de modo coherente, la adecuación entre la teoría y lo observado en la experiencia (empirical fit) que permite iluminar cada vez nuevos ámbitos de realidad, además de la simplicidad, la elegancia y la belleza de la teoría ${ }^{14}$.

Sin embargo, por otro lado, para McGrath hay por lo menos uno de estos marcos interpretativos, el del cristianismo, que no crea el sentido del mundo, sino que lo descubre en su dimensión más profunda: permite ver las cosas como son realmente ${ }^{15}$.

El cristianismo ofrece un sol intelectual que ilumina un mundo que de otra manera sería oscuro y enigmático: provee un "ajuste empírico" (empirical fit) profundamente satisfactorio entre la teoría y la observación, lo cual sugiere que el mapa de la realidad que brinda es confiable y puede ser creído ${ }^{16}$.

Así, hay un sentido profundo que es inherente a la realidad y no es una simple construcción de los seres humanos. ¿Por qué no es entonces evidente para todos, o mejor, por qué son posibles diferentes marcos interpretativos (como los de las diversas religiones) que al menos en apariencia funcionan para organizar y dirigir la vida de miles de personas? Adicionalmente, ¿̇si el sentido es inherente a lo real y no es una proyección efectuada por nuestros esquemas conceptuales y marcos interpretativos, por qué necesitamos estos marcos para "descubrirlo"? ¿Por qué no es suficiente con ver directamente el mundo para captar su sentido?

Por otra parte, si la estructura lógica de las explicaciones religiosas es abductiva -como afirma McGrath-, entonces la verdad de una visión religiosa es siempre apenas probable: es una opción entre muchas. En efecto, el hecho de que un marco pueda dar más sentido que otras visiones rivales es tan solo un indicador de que así pueden ser las cosas. No hay una conexión necesaria entre la capacidad de un relato o una explicación de dar sentido a una situación o a un fenómeno enigmático y su verdad.

Sin embargo, si el sentido de lo real es inherente a lo real mismo y este puede ser descubierto por un relato más verdadero que los otros - para McGrath el del cristianismo-, ¿no estaríamos justificados en esperar una comprobación de la verdad del sentido más fuerte que la que permite una inferencia a la mejor explicación?

Finalmente, ¿cómo encaja la revelación en la lógica abductiva de la visión cristiana de lo real? Porque la estructura de una inferencia a la mejor explicación pone

\footnotetext{
${ }^{14}$ McGrath, Surprised by Meaning. Science, Faith and How We Make Sense of Things, 11, 28, 50.

${ }^{15}$ Ibíd., 51.

${ }^{16}$ Ibíd., 57. Mi traducción.
} 
todo el énfasis en la actividad del intelecto humano para imaginar alternativas de respuesta a una situación enigmática, alternativas que gravitan enteramente sobre la creatividad humana y no reconocen un momento de manifestación del sentido divino, un momento de encuentro con algo dado que escapa a la actividad intelectual y a la voluntad humana.

Estas cuestiones apuntan a lo que a mi modo de ver representa el corazón del problema del sentido en el pensamiento actual. Dado que las explicaciones científicas pueden comprenderse como parte de la más amplia tarea de generar sentido, la cual no puede ya corresponder exclusivamente a la religión, la pregunta es más bien si -en esta empresa humana conjunta- el sentido es entera y meramente un producto humano, sujeto totalmente a las contingencias de la historia, la sociedad y la cultura, o si puede hablarse de un orden de sentido dado y trascendente que informa y dirige toda actividad humana de descubrimiento, conocimiento y comprensión.

Ciertamente existe una tendencia dominante en el pensamiento contemporáneo que afirma la primera opción. Aquí encontramos un foco fuerte y profundo de desacuerdo, no ya entre las ciencias naturales y la religión, sino entre las ciencias sociales contemporáneas y el teísmo en general. Se trata aquí del conflicto entre dos visiones comprehensivas de la realidad que involucran una interpretación del origen del sentido del mundo, de la vida y de la ciencia natural misma, las cuales no parecen conciliarse fácilmente. Por esto, el diálogo es aquí una tarea urgente a la cual este artículo pretende contribuir.

\section{El presupuesto socioconstruccionista sobre el origen del sentido en las ciencias sociales actuales}

La idea según la cual todo sentido es exclusivamente un producto humano bien merece el título de un presupuesto de la Modernidad. Desde Descartes, la actividad de la subjetividad no solo garantiza y hace posible el conocimiento del mundo exterior, sino que goza de una prioridad ontológica sobre este, de cuya existencia independiente no podemos estar nunca seguros del todo.

Si bien el siglo XX celebró "la muerte" del sujeto moderno, cuyo carácter trascendental permitía recuperar la objetividad en la constitución de la realidad, la idea misma del carácter constituido de la realidad sobrevivió al sujeto ${ }^{17}$. El lenguaje, la cultura, las estructuras sociales, las relaciones de poder tomaron su lugar. En efecto, desde las últimas décadas del siglo XX el socioconstruccionismo se consolidó como el paradigma dominante en las ciencias sociales. De acuerdo con esta familia de teorías

\footnotetext{
${ }^{17}$ Grondin, Del sentido de la vida. Un ensayo filosófico, 44, 49.
} 
y enfoques, todo orden de sentido, ya se trate de una visión de mundo religiosa, una teoría científica o cualquier sistema de valor y pensamiento, tiene su origen en una suerte de actividad autoconstitutiva por medio de la cual los seres humanos se construyen a sí mismos tanto como al mundo.

La realidad, en cuanto es humanamente vivida, es meramente un producto humano. La diversidad y la permanente transformación de visiones de mundo, religiones, culturas y estructuras sociales es comprendida como una señal de que lo que cuenta como real y natural solo lo es al interior de una forma de vida o un esquema conceptual enteramente contingente ${ }^{18}$.

La metáfora de la construcción social implica la idea según la cual, en el principio de aquello que cuenta como real, la acción humana juega el papel primordial. Nuestros modos de conocer, el lenguaje, el discurso o la práctica constituyen la realidad antes de descubrirla, representarla o basarse en ella. La cuestión no es, claro está, que nuestras palabras, conceptos y creencias acerca del mundo sean socialmente construidos en el sentido de que no pueden escapar a la influencia histórica y cultural del contexto en el cual se encuentran situados, sino que dada tal situación no pueden referirse a ninguna realidad extracultural o extradiscursiva.

Esto implica la tesis central de las posturas socioconstruccionistas según la cual lo que parece dado, natural e inevitable, "pudo no haber existido o podría ser de un modo diferente a como es [pues] no está determinado por la naturaleza de las cosas"19.

Así, la contingencia es la característica básica de lo que se considera socialmente construido. Esta parece implicar tres tesis ontológicas: (1) lo que es construido debe su existencia a un lenguaje, una cultura o un esquema conceptual particular y transitorio que, incapaz de captar cómo son las cosas, las constituye para servir ciertos intereses y necesidades; (2) lo que es construido no es necesario ni inevitable, pues no es por naturaleza (antiesencialismo); y (3) depende de la actividad humana, mediante prácticas discursivas y culturales, construir, deconstruir o reconstruir la realidad ${ }^{20}$.

Aunque no existe consenso en la literatura socioconstruccionista acerca de cómo se lleva a cabo el proceso de construcción social, vale la pena señalar que los candidatos que comúnmente se presentan como responsables del proceso (la cultura,

\footnotetext{
${ }^{18}$ Para esta sección me baso en Gómez, "In the Beginning Was the Deed? Discovering the Presence of the Spirit in Social Construction", artículo en el que desarrollo con mayor detalle la crítica al socioconstruccionismo.

${ }^{19}$ Hacking, The Social Construction of What? 6 (mi traducción); Burr, Social Constructionism, 45.

${ }^{20}$ Gómez, "In the Beginning Was the Deed? Discovering the Presence of the Spirit in Social Construction", 57.
} 
el lenguaje, el discurso y el conocimiento) ${ }^{21}$ tienen en común que se conciben como formas de práctica. En efecto, como ha señalado adecuadamente Stephen Turner:

En los escritos posfundacionalistas en las humanidades la diversidad de las prácticas humanas ha venido a ocupar el lugar y a llenar el vacío que antiguamente ocupaban las nociones fundacionalistas tradicionales como verdad, validez e interpretación correcta. Verdad, validez y corrección son consideradas como nociones relativas a una práctica, en lugar de la justificación de las prácticas. Solíamos afirmar que nuestras prácticas, por ejemplo, la ciencia, eran justificadas por el hecho de que conducían a la verdad. Ahora consideramos que la verdad es solo aquello que nuestras prácticas de representación nos permiten construir como verdadero. Dado que las prácticas son diversas y locales, la verdad y la validez también son locales y "socialmente construidas". ${ }^{22}$

El concepto de práctica es multifacético y polisémico; pero, desde el punto de vista socioconstruccionista, una práctica se puede definir como un patrón de acciones habitualizadas carentes de un fundamento (no basadas en la esencia o en la naturaleza de las cosas o las personas), más profundo que la actividad humana misma, que gozan del poder de producir (construir, inventar, generar) la realidad (el conocimiento, los sujetos, el mundo social).

Sin embargo, ¿cómo pueden las prácticas -que son de suyo patrones de actividad significativa- ser el centro del proceso de la construcción social de los universos de sentido? Desde mi punto de vista, rastrear esta pregunta nos permite ver hasta qué punto el origen del sentido no se deja reducir a la acción humana, pues ninguna práctica o proceso de construcción del sentido puede autosostenerse ni autosoportarse.

En breve, mi argumento es el siguiente: las prácticas no son simplemente secuencias de acciones (por ejemplo, instintivas o automáticas), sino que se articulan en patrones de comportamiento intencional y comprensible. En este sentido, las prácticas requieren de la habitualización de ciertas acciones y algo así como de su codificación. Por tanto, ellas presuponen el orden de sentido del mundo social al que pertenecen $\mathrm{y}$ al cual contribuyen a reproducir y transformar.

Esta circularidad del sentido, es decir, el hecho de que las prácticas sean de suyo significativas dentro de un cierto horizonte de precomprensión (cuya construcción supuestamente las prácticas mismas deberían poder explicar) es una señal de que ninguna práctica puede autosoportarse ni autofundarse.

Exploremos con detalle esta circularidad en una obra que contribuyó a establecer el paradigma socioconstruccionista, sin ser ella misma todavía una expresión radical

${ }^{21}$ Elder-Vass, The Reality of Social Construction.

${ }^{22}$ Turner, The Social Theory of Practices. Tradition, Tacit Knowledge and Presuppositions, 9. Mi traducción. 
de este paradigma: se trata del libro clásico de Peter Berger y Thomas Luckmann, The Social Construction of Reality. A Treatise in the Sociology of Knowledge. Este da cuenta del origen social de la realidad, o como ellos dicen, del sentido de realidad y objetividad de aquellas estructuras del mundo social que percibimos como teniendo una existencia independiente de nosotros ${ }^{23}$. Para esto proponen una narrativa de acuerdo con la cual la realidad social es construida mediante un proceso que sigue tres momentos: la externalización, la objetivación y la interiorización. Consideremos cada uno con algún detalle.

Dada la plasticidad propia del comportamiento del ser humano, que hace que su relación con el medio ambiente -a diferencia de lo que ocurre con otras especiesno esté enteramente determinada por los instintos sino que puede adquirir múltiples formas y direcciones, la exteriorización es casi una "necesidad antropológica" de actuar en el mundo exterior para fijar de algún modo sus cursos de su acción. En este sentido, dado que el organismo humano se halla "muy imperfectamente estructurado por su propia constitución biológica", "el ser humano construye su propia naturaleza, o más simplemente el ser humano se produce a sí mismo"².

Sin embargo, evidentemente, esta autoproducción no ocurre en una suerte de vacío cultural primigenio. Antes bien, es de suyo una empresa social en cuanto que los seres humanos deben terminar su desarrollo ontogenético, luego de que han nacido, en relación con un particular ambiente sociocultural, el cual es justamente lo que provee la estabilidad a la conducta humana que esta carece debido a su plasticidad primordial ${ }^{25}$. De tal modo, la externalización no puede estar en el principio (en el origen) del proceso de construcción de la realidad social porque requiere de un orden social previo para funcionar.

Aquí aparece ya claramente la circularidad propia de todo intento por explicar el origen del sentido mediante la referencia a algún tipo de acción presignificativa. Tal vez por esto muchos socioconstruccionistas prefieren simplemente aceptar el regreso al infinito de las construcciones y afirmar que carece de sentido preguntarse por un punto cero del proceso.

No obstante, esto resulta problemático en los propios términos de tales teorías. Por ejemplo, es verdad que Berger y Luckmann insisten en que la relación entre los seres humanos y la sociedad es dialéctica, pues cada uno es un producto del otro, de modo que es impensable un comienzo radical del orden social en un estado presocial

\footnotetext{
${ }^{23}$ Berger y Luckmann, The Social Construction of Reality. A Treatise in the Sociology of Knowledge, 1.

${ }^{24}$ Ibíd., 49. Mi traducción.

${ }^{25}$ Ibíd., 51.
} 
de la humanidad; pero simultáneamente la teoría pretende explicar cómo la realidad social es un producto de la actividad humana. La cuestión no es solo que la realidad social sea reproducida, sino que se busca mostrar cómo es construida, es decir, cómo los seres humanos crean su propia naturaleza y su mundo ${ }^{26}$. Y esto es justamente lo que nunca se logra hacer.

Los dos momentos siguientes, la objetivación y la interiorización, simplemente continúan dicha dinámica. El movimiento de la externalización conlleva a la instauración de patrones y rutinas de acción que se han vuelto repetitivas, es decir, a la creación de hábitos. Estos reducen el ámbito de las acciones posibles y hacen posible una dirección y especialización de la actividad que el mero instinto no puede proveer a los seres humanos.

Consecuentemente, las acciones habitualizadas son institucionalizadas mediante la tipificación de actores, es decir, mediante la asignación recíproca de fines y motivos, lo cual permite dirigir, controlar y predecir la conducta de otros actores que comparten el mismo modo de tipificar la acción ${ }^{27}$. Y cuando es necesario transmitir estos patrones de acción institucionalizados a la siguiente generación, se cristalizan. A esto Berger y Luckmann dan el nombre de "objetivación", pues las instituciones son experimentadas por las personas como si tuvieran una realidad propia que "confronta a los individuos como un hecho externo y coercitivo" ${ }^{28}$.

El tercer momento es la "internalización" de las normas y patrones que constituyen el mundo social así construido. Es aquí cuando por primera vez el lenguaje cumple una función en todo el proceso. En efecto, para Berger y Luckmann, aquí se encuentra el origen de los universos de sentido, desde el mito y la filosofía hasta la moral. Estos aparecen como mecanismos de legitimación que sirven para explicar y justificar a las nuevas generaciones el orden creado $^{29}$. Su función consiste en proveer una narrativa unificada sobre el sentido de las acciones institucionalizadas que gradualmente constituye el conocimiento preteórico del mundo social, es decir, lo que todos toman por dado y sirve para regular el comportamiento.

De este modo, además de brindar la orientación necesaria para la sobrevivencia, este horizonte común de sentido genera un mundo público en el cual es posible la vida

${ }^{26}$ Gómez, "In the Beginning Was the Deed? Discovering the Presence of the Spirit in Social Construction”, 69.

${ }^{27}$ Berger y Luckmann. The Social Construction of Reality. A Treatise in the Sociology of Knowledge, 57.

${ }^{28}$ Ibíd., 58 (mi traducción).

${ }^{29}$ Ibíd., 62; 65ss. 
social. Al mismo tiempo, sirve para dar coherencia y plausibilidad tanto a la totalidad del orden social como a cada vida individual ${ }^{30}$.

Como ya indicamos, el problema con esta teoría es justamente que no ha sido capaz de mostrar que tal horizonte de sentido que provee coherencia y orientación a la vida humana es simplemente producto de la externalización, o mejor, de algún tipo de acción presignificativa; pues, dado que las acciones que se tipifican son ya los actos significativos de actores previamente socializados, la acción habitualizada que constituye una práctica presupone siempre un horizonte de precomprensión en el que se integra.

Consecuentemente, lo que ha sido descrito es tan solo el modo como un nuevo orden de sentido puede surgir de la interacción entre actores provenientes de diferentes universos culturales. Berger y Luckmann explícitamente reconocen esto al afirmar que los dos individuos que utilizan en su modelo hipotético para dar cuanta de todo este proceso "provienen de mundos sociales que han sido históricamente producidos aisladamente," con la salvedad única de que, por esto, "la interacción entre ellos tiene lugar en una situación que no ha sido definida institucionalmente por ninguno de los participantes." ${ }^{31}$ Indudablemente, la nueva interacción debe aún institucionalizarse, pero esto solo es posible sobre la base de los horizontes de sentido previos de cada uno.

Desde mi perspectiva, esta preeminencia del sentido puede interpretarse como señal de un rasgo fundamental de la naturaleza de la acción humana y del carácter fundante del sentido. Podríamos denominar esta preeminencia -es decir, que el sentido siempre tenga que ser presupuesto de un modo u otro y que su origen no se deje reducir a la acción presignificativa- con el término "trascendencia" ${ }^{32}$.

Esto es precisamente algo que la conciencia religiosa en diversas tradiciones ha descubierto y expresado. Mas la vacilación entre el primer versículo del Evangelio de Juan ("En el principio existía la Palabra") y el modo como el doctor Fausto quiso traducirlo (“¡En el principio era la acción!”33) continúa siendo una tensión constitutiva de la autocomprensión del hombre moderno.

\footnotetext{
${ }^{30}$ Ibíd., 94.

${ }^{31}$ Ibíd., 57.

${ }^{32}$ Gómez, "In the Beginning Was the Deed? Discovering the Presence of the Spirit in Social Construction", 70.

${ }^{33}$ Goethe, Fausto, 143.
} 


\section{La trascendencia del sentido como eje de la relación entre las ciencias y la visión cristiana de la realidad}

Como dijimos en la primera parte, si la tarea de explicar el orden causal y la estructura de la realidad y la de descubrir su sentido no pueden nunca separarse del todo, de modo que ciencia y religión hacen parte de esfuerzos solidarios y complementarios, entonces el hecho de que haya una fuente de sentido trascendente respecto de la actividad humana tiene un impacto sobre el modo mismo como podemos comprender la labor de las ciencias y su relación con las formas de conocimiento religioso. Para terminar, quisiera señalar brevemente algunos campos en los que las ciencias y la religión -en particular el cristianismo- pueden encontrar hoy un terreno común para el diálogo sobre el sentido de lo real.

\section{Respecto de las ciencias naturales: realismo y teísmo}

Toda investigación de la realidad parte de una visión del ámbito de la realidad estudiado que nunca es un resultado de la investigación misma, sino su presupuesto. Este es uno de los grandes aportes de filósofos como Wittgenstein, Heidegger, Husserl y Polanyi, quienes trataron de explorar la dimensión tácita de nuestro pensamiento y acción. En el caso de las ciencias, la investigación de la naturaleza se basa en una interpretación de aquello en que consiste el orden natural, del cual se deriva una particular manera de estudiarlo ${ }^{34}$.

En esta dirección, Michael Foster propuso una tesis sobre el surgimiento de la ciencia moderna que ha sido ampliamente discutida en los estudios sobre las relaciones entre ciencia y religión. Para este filósofo de Oxford, la visión de la naturaleza como orden creado contribuyó a generar un modo de comprensión de la realidad que hizo posible la investigación empírica del mundo ${ }^{35}$.

Esto es así porque a diferencia del mundo eterno de los griegos, en el que solo son objeto de la ciencia las esencias, es decir, las formas inteligibles que deben ser definidas racionalmente y que se encuentran encarnadas en una materia que no aporta nada al conocimiento, una naturaleza creada requiere ser investigada mediante

\footnotetext{
${ }^{34}$ Múnera, Meléndez y Gómez, "La doctrina de la creación como espacio para el diálogo entre las ciencias y el cristianismo".

${ }^{35}$ Foster, "The Christian Doctrine of Creation and the Rise of Modern Natural Science". Para ampliar esta discusión pueden verse los artículos publicados en Luis F. Múnera, Raúl Meléndez y Carlos Miguel Gómez (eds.), en Ciencia y creación. La investigación científica de la naturaleza y la visión cristiana de la realidad; y en McGrath, $A$ Scientific Theology: Nature.
} 
métodos empíricos y no meramente deductivos. El presupuesto básico de la ciencia moderna, según el cual la evidencia empírica es la fuente primordial del conocimiento, solo es posible si el contingente mundo material no se concibe como lo opuesto de lo ininteligible, sino que, en cuanto es obra de Dios, tiene realidad y sentido.

La actividad voluntaria del Creador (esto es, aquello en su actividad que excede la determinación por la razón) culmina en el ser contingente de la criatura (esto es, en aquel elemento de su ser que escapa a la determinación por medio de la forma, a saber, su materia y las características que posee en cuanto material). $\mathrm{Si}$ tal actividad voluntaria es esencial a Dios, se sigue que el elemento de la contingencia es esencial a lo que él crea. Tan pronto la naturaleza es concebida como creada por Dios, lo contingente llega a ser más que una imperfección en la encarnación de la forma; es precisamente lo que constituye a un objeto natural como algo más que una encarnación, a saber, una criatura. ${ }^{36}$

Así, porque lo contingente es un rasgo esencial de la naturaleza, y este solo puede ser estudiado empíricamente, la ciencia de la naturaleza debe ser de suyo una ciencia empírica. De hecho, justamente porque la naturaleza es creada hay en ella algo (lo que es resultado de la voluntad libre del Creador) que no puede ser captado directamente por la sola razón, como una necesidad lógica, sino que requiere ser descubierto en el mundo mismo, como seńal e indicación de los rasgos y la voluntad del Creador.

Además, la creencia en que el mundo es obra de Dios proveyó el presupuesto básico de la investigación científica: la creencia en la inteligibilidad de la naturaleza y en la capacidad de la mente humana para descifrarla. Como es sabido, los padres de la ciencia moderna en el siglo XVII encontraron una motivación y una justificación para su labor investigativa en la creencia en que la naturaleza, en cuanto creada por Dios, poseía un carácter ordenado y accesible a la investigación racional. Estudiar la obra permitía conocer a su creador.

La metáfora de los dos libros e incluso el origen de la idea misma de las "leyes naturales", que implican la creencia en la existencia de un autor y legislador del universo, son célebres en este respecto. En efecto, la posibilidad del conocimiento se explicó durante mucho tiempo a partir de la homogeneidad entre la mente humana y el mundo, garantizada porque la mente había sido creada con una estructura semejante y capaz de captar y corresponder con la de la realidad, en cuanto ambas son obras del mismo autor ${ }^{37}$.

\footnotetext{
${ }^{36}$ Foster, "The Christian Doctrine of Creation and the Rise of Modern Natural Science", 464.

${ }^{37}$ Brooke, Science and Religion. Some Historial Perspectives, 19ss.; McGrath, A Scientific Theology: Nature, Capítulo 5.
} 
Pero, si bien la imagen de la naturaleza como orden creado desempeñó un papel central en el desarrollo histórico de la ciencia moderna, la situación de la epistemología actual requiere que repensemos estos presupuestos de la inteligibilidad y el orden del mundo. En particular, ¿cómo podemos reinterpretar la doctrina de la creación de modo que integre y dé sentido al permanente cambio de paradigmas científicos, a la historicidad del conocimiento y, en general, a las críticas bien fundamentas a los modelos correspondentistas y representacionalistas de la verdad y el conocimiento?

La discusión epistemológica actual no permite ya una imagen ingenua del conocimiento científico como una relación directa de correspondencia entre la mente y el mundo hecha posible por su homogeneidad estructural. Por un lado, encontramos las repetidas críticas a la teoría tradicional de la verdad como una relación de adaequatio entre la mente o nuestras teorías y el mundo. Hay dos argumentos célebres al respecto.

El primero tiene que ver con la crítica a la noción misma de correspondencia, que nunca ha podido ser explicada del todo. ¿Qué tipo de relación es esta entre dos órdenes tan diferentes como el de los conceptos y el lenguaje, por un lado, y el de los objetos materiales y las relaciones causales por el otro? ¿Cómo pueden concordar en algún sentido ambos dominios y qué significa propiamente esta concordancia? La incapacidad de responder a tales preguntas ha hecho de la noción misma de correspondencia algo vago y vacío ${ }^{38}$.

El segundo argumento señala que es imposible evaluar la correspondencia entre nuestras teorías y el mundo que pretenden describir, simplemente porque no podemos salir de nuestro lenguaje y esquemas conceptuales para encontrar un lugar neutral desde el cual comprobar la correspondencia ${ }^{39}$. En efecto, es imposible desvincular los "hechos" del lenguaje y el andamiaje conceptual que utilizamos para describirlos, de modo que los primeros no pueden servir para evaluar los segundos. Dado que nuestro acceso al mundo es mediado por nuestras interpretaciones, todo lo que podemos hacer es ofrecer razones, haciendo uso de los recursos conceptuales de un lenguaje y un esquema conceptual históricamente situado, en favor o en contra de una teoría.

Como consecuencia, la verdad o falsedad de lo que decimos sobre el mundo permanecen ligadas a los mecanismos de justificación con que contamos, incluso si reconocemos que es necesario mantener abierto el proceso de justificación y crítica hacia el infinito, para evitar identificar ligeramente la verdad con aquello que resulta aceptable para un grupo social en un momento determinado ${ }^{40}$. Más aún, mientras

\footnotetext{
${ }^{38}$ Putnam, Reason, Truth and History, 51; Heidegger, Ser y tiempo \$44, 232.

${ }^{39}$ Putnam, Reason, Truth and History, 49ss.

${ }^{40}$ Ibíd.; Habermas, "Realism after the Pragmatic Turn”, 36ss.
} 
que es posible refutar una teoría mediante razones, se nos escapa la posibilidad de una prueba o demostración absoluta e inmune contra toda refutación. Por el contrario, es uno de los méritos de Karl Popper haber señalado que la posibilidad de falsear una teoría constituye la marca de su carácter científico.

Por el otro lado, la noción misma del conocimiento como representación de la realidad ha sido puesta en cuestión. Al seguir las intuiciones básicas del pragmatismo norteamericano, un gran número de filósofos afirma hoy que nuestros conceptos y teorías deben comprenderse, más que como imágenes que pretenden copiar un aspecto de la realidad, como respuestas a problemas prácticos y formas de actuar sobre el mundo para responder a intereses y necesidades concretos ${ }^{41}$. Esto implica una inversión de la forma como tradicionalmente se dio primacía a la teoría sobre la práctica, de modo que la teoría misma no solo es el resultado de maneras de actuar y vivir en el mundo, sino que de suyo es un tipo de actividad interesada.

La cuestión que resulta importante para nuestra reflexión es precisamente la manera como se comprende la práctica teórica y, en particular, el lugar y el significado de la acción creativa de los seres humanos en todo el proceso. Desde mi punto de vista, una fuerte tendencia en el pensamiento contemporáneo concluye de manera apresurada que, dado que todo conocimiento está anclado a prácticas sociales movidas por intereses y necesidades concretas, entonces no puede decirnos nada acerca de cómo son las cosas independientemente de nosotros, sino que más bien construye lo que cuenta como real para un grupo social determinado ${ }^{42}$.

"Estamos confinados a las maneras de describir cualquier cosa que sea descrita. Nuestro universo, para hablar de algún modo, consiste en estas maneras de describir en lugar que en un mundo de mundos”33, afirma Nelson Goodman de una manera que bien representa una extendida posición filosófica en la actualidad.

Dejando de lado los problemas filosóficos de esta tendencia que ha venido a denominarse antirrealismo ( $\mathrm{y}$ de la cual el socioconstruccionismo al que nos referimos antes es una versión radical) quisiera señalar aquí que esta posición es incompatible con el teísmo. La razón principal de esta incompatibilidad es la incapacidad de tal postura para reconocer y dejarse interpelar por toda otredad y, en particular, por toda alteridad extrahumana dadora de forma, dirección y sentido.

Solo la acción humana, mediante el lenguaje, la cultura, el discurso, configuran la realidad. Todo sentido es una invención y creación sociales ante un mundo que

\footnotetext{
${ }^{41}$ Ibíd., 30ss.

${ }^{42}$ Para una crítica a esta posición ver a Gómez, "Historicidad, Realismo y verdad”, 77-98.

${ }^{43}$ Goodman, Ways of World Making, 3.
} 
carece en sí de estructura o que permanece inaccesible más allá de nuestros conceptos, incapaz de manifestarse significativamente. Aquí se consuma una de las tendencias más características del espíritu moderno: la realidad entera gira en torno del ser humano, que ahora también ya carece de una naturaleza diferente a la que él mismo pueda darse mediante prácticas contingentes. Más aún, la realidad misma es constituida por el sujeto, ahora vacío de esencia, disuelto en lenguaje, acción o impulso autoconstituyente.

El teísmo, por el contrario, exige el reconocimiento de un Otro en sentido fuerte, es decir, de Dios como dador de sentido y orden primordiales en relación con quien somos y podemos, también históricamente, reconstruirnos siguiendo un llamado y una vocación. ¿Cómo podemos comprender esta relación dadora de sentido de modo que responda a nuestra autocomprensión contemporánea tan determinada por la conciencia de la historicidad y la contingencia del conocimiento? O, puesto de otra manera, ¿cómo podemos ofrecer una interpretación del conocimiento que acoja las críticas a la imagen correspondentista y representacionalista, y a la vez sea compatible con las existencias realistas propias del teísmo?

Estas preguntas representan uno de los grandes retos para la teología y la filosofía de la religión del presente. Se trata de repensar la cuestión del sentido del mundo natural, cuyo origen se encuentra en la acción creadora de Dios, de modo que se incluya la acción cocreadora de la inteligencia humana, sin que esto implique concluir que todo sentido es mera invención humana. No puedo aquí más que anotar una intuición básica que requiere de un cuidadoso desarrollo: en el carácter relacional e histórico del conocimiento, en el cual la autocompresión contemporánea da el lugar primordial al papel activo del sujeto cognoscente y, en algunas tendencias actuales, se exacerba hasta convertirlo en $e l$ constructor de la realidad, es ya posible redescubrir la presencia de un sentido trascendente ${ }^{44}$.

Ciertamente resulta del todo inaceptable una teoría que, luego de pretender mostrar cómo mediante ciertas prácticas históricas ha surgido una particular interpretación que es luego asumida como la realidad misma, en un determinado tiempo y lugar, afirme que ella misma es solo una forma de construir su objeto, el cual no tiene ninguna realidad independiente de la teoría.

Por el contrario, ciertos presupuestos acerca del carácter histórico del conocimiento y el ser humano, así como sobre sus capacidades de construir la realidad mediante prácticas y teorías deben ser siempre asumidos simplemente como verdaderos en

\footnotetext{
${ }^{44}$ Desarrollo este argumento en Gómez, "In the Beginning Was the Deed? Discovering the Presence of the Spirit in Social Construction".
} 
este tipo de teorías, si acaso pretenden hablar con sentido ${ }^{45}$. Este nivel de los presupuestos metafísicos que son tomados por dados por una teoría representa uno de los lugares primordiales para el diálogo entre las ciencias y el cristianismo.

Justamente en el "hecho" de que la realidad es para los seres humanos relacional, es decir, en la medida en que es inacabada y nosotros estamos abocados a participar en ella para completarla, es posible descubrir al menos una parte del sentido del tipo de seres que somos y del tipo de mundo en el que vivimos. A la vez, en la medida en que -como sugerimos en el apartado anterior- este proceso requiere siempre de un sentido dado y anterior que guía y dirige el proceso de reconstrucción de la realidad, es necesario comprendernos como cocreadores creados ${ }^{46}$.

El proceso mismo mediante el cual producimos lo real mediante nuestras prácticas (el cual es siempre limitado por las exigencias de la naturaleza, que impone su alteridad y se resiste a muchas de nuestras interpretaciones) es parte de la realidad. Esto quiere decir que tiene un modo de ser en el que, desde el punto de vista del cristianismo y del teísmo en general, puede discernirse una manifestación de la voluntad de Dios que nos crea para colaborar con su obra creadora del mundo y de nosotros mismos.

\section{Respecto de las ciencias humanas: imago Dei y construcción social}

En el ámbito de las ciencias sociales, hoy parecería inaceptable reintroducir una dimensión trascendente de sentido en el mundo humano. Sin embargo, las aporías y problemas irresueltos del paradigma socioconstruccionista, de los cuales nos hemos referido solo a la circularidad del sentido, parecen hacerlo posible ${ }^{47}$.

Desde el punto de vista cristiano, aquí la cuestión es reinterpretar la doctrina de la imago Dei de modo que integre, dándole sentido y dirección, pero también poniéndole un límite, la intuición básica del socioconstruccionismo y las antropologías contemporáneas, según la cual el ser humano se constituye a sí mismo históricamente mediante la actividad, la cultura y el lenguaje. ${ }^{48}$

Indudablemente resulta insuficiente para esta tarea una interpretación estructural de la imago Dei, según la cual lo propiamente humano, aquello que constituye

${ }^{45}$ Smith, What is a Person? Rethinking Humanity, Social Life, and the Moral Good from the Person Up, Capítulo 3.

${ }^{46}$ Hefner, The Human Factor: Evolution, Culture and Religion, 23 ss.

${ }^{47}$ Para otras críticas ver a Kukla, Social Constructivism and the Philosophy of Science, a Boghossian, Fear of Knowledge. Against Relativism and Constructivism, y la discusión que adelanta Smith, What is a Person? Rethinking Humanity, Social Life, and the Moral Good from the Person Up, Capítulo 3.

${ }^{48}$ Gómez, "In the Beginning Was the Deed? Discovering the Presence of the Spirit in Social Construction" 
la imagen del Creador en nosotros, sería una propiedad o un atributo plenamente configurado, universal y ahistórico, como una estructura racional pura y eterna, o una configuración moral basada en la libertad o sentimientos como el amor, la misericordia o la justicia. ${ }^{49}$

Aquello que nos hace humanos no puede ser comprendido en un sentido substancialista incapaz de reconocer nuestra fundamental historicidad y capacidad autocreativa, las cuales, en cuanto representan nuestra finitud, son lo que nos diferencia del ser divino. Mientras que la naturaleza divina, en su plenitud y eternidad, puede considerarse como predada, los seres humanos debemos hacernos a nosotros mismos, como han insistido autores como Marx, Sartre o Heidegger, mediante la actividad y la interacción con el mundo y los otros seres humanos ${ }^{50}$. Esta diferencia ontológica fundamental hace que la imagen y semejanza de Dios en el ser humano no pueda concebirse como una esencia eterna e inmutable de lo humano, dada desde el origen y si acaso desfigurada por la caída.

Una interpretación relacional de la imago Dei, por otra parte, según la cual lo que nos hace propiamente humanos es nuestra relación con Dios (la cual hace posible y orienta nuestra relación con otras personas y el mundo) ${ }^{51}$, si bien tiene la ventaja de permitir e incorporar hasta cierto punto el dinamismo y la variación propios de la historicidad, no lo hace aún de modo suficiente. Esto es así porque las formas y tipos de relación humana que estas teorías asumen como modelo y copia de la relación original con Dios (y de la relación entre las tres personas de la Trinidad, que sería el arquetipo de toda relación auténticamente humana), tales como la relación entre hombre y mujer, son justamente las que la autocomprensión contemporánea descubre como contingentes e históricas.

Más prometedores resultan aquí los denominados enfoques prolépticos de la imago Dei, los cuales ponen el énfasis en el hecho de que la creación divina es un acto continuado a través de la historia, en el que participamos los seres humanos como cocreadores $^{52}$. En este sentido, Wolfhart Pannenberg ha llamado la atención sobre el

\footnotetext{
${ }^{49}$ En la literatura actual se suelen clasificar las interpretaciones tradicionales de la imago Dei en teorías estructurales o substantivas (que identifican la imagen y semejanza con alguna propiedad de los seres humanos), funcionalistas (que la ven algún modo de actuar y comportarse) y relacionales. Ver a J. de Smedt y H. de Cruz, "The Imago Dei as a Work in Progress: A Perspective from Paleoanthropology", 136; y a Van Huyssteen, Alone in the World? Human Uniqueness in Science and Theology, 116- 145.

${ }^{50}$ Clayton, Adventures in the Spirit. God, World, Divine Action, 180.

${ }^{51}$ Peters, God, The World's Future. Systematic Theology for a New Era, 154; Van Huyssteen, Alone in the World? Human Uniqueness in Science and Theology, 136ss.

52 Peters, God, The World's Future. Systematic Theology for a New Era,147-159; Van Huyssteen, Alone in the World? Human Uniqueness in Science and Theology, 139.
} 
hecho de que el concepto de "naturaleza" humana es más griego que propiamente cristiano, pues lo que el ser humano verdaderamente es -antes que una esencia dada enteramente desde el principio- consiste más bien en lo que está llamado a ser en el futuro escatológico y mediante la mediación salvífica de Dios ${ }^{53}$.

La imago Dei es entonces el resultado de la nueva creación y se identifica con el "segundo hombre" al que se refiere San Pablo (1 Co 15, 47). Se trata de un llamado y un proyecto, una tarea y una vocación que debe ser realizada históricamente y en la que participamos como cocreadores guiados por el sentido eterno.

Esta tarea de cocreación guiada por el sentido, por supuesto, no debe ser entendida como una suerte de predeterminación del curso de la historia, ni como una teleología estática, que no permiten la creatividad ni la variabilidad propia de la actividad humana. Más bien, como afirma Pannenberg, se trata de

...una comprensión de Dios como la meta de la historia [...] y una comprensión de los fines de Dios en su trato con los seres humanos puede inspirar su anticipación de la forma final de la identidad humana y así [proveer] el marco de orientación en el cual [los seres humanos] deciden los fines de sus propias

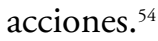

De este modo, la idea de un sentido dado y trascendente resulta compatible con la intuición socioconstruccionista acerca del carácter autocreativo del ser humano, pero de modo que la inscribe y sitúa en un horizonte mayor en el que aparece como una tarea de construcción de sí mismo, inspirada por la comprensión de la voluntad divina, para la cual el ser humano ha sido creado.

\section{Conclusión}

Aquí se ha procurado mostrar que, dada la imposibilidad de mantener la clásica dicotomía entre explicar y comprender, esta no puede emplearse para delimitar los dominios de las ciencias naturales y sociales y la religión, en particular el teísmo cristiano. En cambio, la cuestión fundamental sobre el origen del sentido y sus implicaciones para el conocimiento y la vida humana representa un lugar de tensión y diálogo posible.

La situación epistemológica actual exige repensar las implicaciones de la doctrina de la creación para nuestra comprensión del conocimiento de la naturaleza y la construcción del mundo humano, de manera que integre y dé sentido a la conciencia de la historicidad y a la contingencia de nuestras formas de conocer y vivir, a la vez

\footnotetext{
${ }^{3}$ Pannenberg, Anthropology in Theological Perspective, 495ss.

${ }^{54}$ Ibíd., 515.
} 
que logre redescubrir la presencia de un sentido trascendente en la naturaleza y las prácticas autoproductivas del ser humano.

He aquí una tarea urgente para la teología y la filosofía de la religión hoy: ayudar al ser humano contemporáneo a comprender y a descubrir en el flujo de la historia la vocación a las que nos llama el sentido eterno, en la experiencia de la transitoriedad de toda forma cultural y en la conciencia de nuestro papel creador y configurador de realidad.

\section{Referencias}

Berger, Peter y Thomas Luckmann. The Social Construction of Reality. A Treatise in the Sociology of Knowledge. New York (NY): Anchor Books, 1967.

Bhaskar, Roy. The Possibility of Naturalism. London: Routledge, 1979.

Boghossian, Paul. Fear of Knowledge. Against Relativism and Constructivism. Oxford: Clarendond Press, 2006.

Brooke, John Hedley. Science and Religion. Some Historial Perspectives. Cambridge: Cambridge University Press, 1991.

Burr, Vivien. Social Constructionism (2.a ed.). London: Routledge, 2003.

Clayton, Philip. Adventures in the Spirit. God, World, Divine Action. Minneapolis (MN): Fortress Press, 2008.

. Explanation from Physics to Theology. New Haven (CN): Yale University Press, 1989.

De Smedt, Johan y Helen De Cruz. "The Imago Dei as a Work in Progress: A Perspective from Paleoanthropology”. Zygon 49, 1 (2014): 135-156.

Elder-Vass, Dave. The Reality of Social Construction. Cambridge: Cambridge University Press, 2012.

Foster, M. B. "The Christian Doctrine of Creation and the Rise of Modern Natural Science". Mind Vol. 43, No. 172 (1934): 446-468. [Artículo publicado en español en: Múnera, Luis Fernando; Raúl Meléndez y Carlos Miguel Gómez, Ciencia y creación. La investigación cientifica de la naturaleza y la visión cristiana de la realidad. Santander-Bogotá-Madrid: Sal Terrae- Editorial JaverianaUniversidad Pontificia Comillas, 2018].

Goethe, Johann Wolfgang. Fausto. Traducción de Pedro Gálvez. Barcelona: Random House Mondadori, 2013. 
Gómez, Carlos Miguel. "Fe y conocimiento. Investigación sobre la función epistémica de la creencia religiosa”. En ¿Ciencia o religión? Exploraciones sobre las relaciones entre religión y racionalidad en el mundo contemporáneo, editado por Raúl Meléndez, Luis Fernando Múnera y Carlos Miguel Gómez, 19-44. Bogotá: Pontificia Universidad Javeriana- Universidad del Rosario, 2017.

. "Historicidad, realismo y verdad". Principia: An International Journal of Epistemology 21, 1 (2017): 77-98.

. "In the Beginning Was the Deed? Discovering the Presence of the Spirit in Social Construction”. Scientia et Fides 6, 1 (2018): 53-77.

Goodman, Nelson. Ways of Worldmaking. Indianapolis (IN): Hackett, 1978.

Grondin, Jean. Del sentido de la vida. Un ensayo filosófico. Barcelona: Herder, 2005.

Habermas, Jürgen. "Realism after the Pragmatic Turn". En Truth and Justification, por J. Habermas, 1-49, editado por Barbara Fultner. Cambridge (MA): MIT Press, 2003.

Hacking, Ian. The Social Construction of What? Cambridge (MA)-London: Harvard University Press: 2000.

Harrison, Peter. The Territories of Science and Religion. Chicago-London: The University of Chicago Press, 2015.

Hefner, Philip. The Human Factor: Evolution, Culture and Religion. Minneapolis (MN): Fortress Press, 1993.

Heidegger, Martin. Ser y tiempo. Traducción de Jorge Rivera. Madrid: Trotta, 2016.

Husserl, Edmund. The Crisis of European Sciences and Transcendental Phenomenology. Evanston (IL): Northwestern University Press, 1970.

Kukla, Andre. Social Constructivism and the Philosophy of Science. London-New York: Routledge, 2000.

McGrath, Alister. A Scientific Theology: Nature. London: T\&T Clark, 2002. . Science and Religion. A New Introduction (2.a ed.). Oxford: Wiley-Blackwell, 2010.

. Surprised by Meaning. Science, Faith and How We Make Sense of Things. Louisville (KY): Westminster John Knox Press, 2011.

Múnera, Luis Fernando; Raúl Meléndez; y Carlos Miguel Gómez. "La doctrina de la creación como espacio para el diálogo entre las ciencias y el cristianismo". 
En Ciencia y creación. La investigación cientifica de la naturaleza y la visión cristiana de la realidad, editado por Luis Fernando Múnera, Raúl Meléndez y Carlos Miguel Gómez, 1-20. Santander-Bogotá-Madrid: Sal Terrae- Editorial Javeriana-Universidad Pontificia Comillas, 2018.

Pannenberg, Wolfhart. Anthropology in Theological Perspective. Edinburg: T\&T Clark: 1985.

Peters, Ted. God, The World's Future. Systematic Theology for a New Era (2. ${ }^{a}$ ed.). Minneapolis (MN): Fortress, 2000.

Phillips, D. Z. Religion withouth Explanation. Hoboken (NJ): Blackwell, 1978.

Plantinga, Alvin. Warranted Christian Belief. New York (NY): Oxford University Press, 2000.

Polanyi, Michael. Meaning. Chicago (IL): University of Chicago Press, 1975.

Putnam, Hilary. Reason, Truth and History. Cambridge: Cambridge University Press, 1981.

Smith, Christian. What is a Person? Rethinking Humanity, Social Life, and the Moral Good from the Person Up. Chicago (IL): University of Chicago Press, 2010.

Smith, Wilfred Cantwell. The Meaning and End of Religion. Minneapolis (MN): Fortress Press, 1991.

Turner, Stephen. The Social Theory of Practices. Tradition, Tacit Knowledge and Presuppositions. Cambridge: Polity, 1994.

Van Huyssteen, Wentzel. Alone in the World? Human Uniqueness in Science and Theology. Göttingen: Vandenhoeck \& Ruprecht, 2006. 